\title{
Episomal HIV-1 DNA and its relationship to other markers of HIV-1 persistence
}

\author{
Javier Martinez-Picado ${ }^{1,2,3^{*}}$ [D, Ryan Zurakowski ${ }^{4}$, María José Buzón ${ }^{5}$ and Mario Stevenson ${ }^{6}$
}

\begin{abstract}
Reverse transcription of HIV-1 results in the generation of a linear CDNA that serves as the precursor to the integrated provirus. Other classes of extrachromosomal viral cDNA molecules can be found in acutely infected cells including the 1-LTR and 2-LTR circles of viral DNA, also referred as episomal HIV-1 DNA. Circulating CD4 ${ }^{+}$T-cells of treatmentnaïve individuals contain significant levels of unintegrated forms of HIV-1 DNA. However, the importance of episomal HIV-1 DNA in the study of viral persistence during antiviral therapy (ART) is debatable. 2-LTR circles are preferentially observed in the effector memory $\mathrm{CD}^{+}{ }^{+} \mathrm{T}$ cell subset of long-term treated subjects. Treatment intensification of standard regimens has been used to determine if more potent ART can impact viral reservoir activity. Adding a potent antiretroviral drug to a stable triple-drug regimen has no measurable impact on plasma HIV-1 RNA levels, suggesting that ongoing cycles of HIV-1 replication are not a major mechanism driving persistent plasma viremia during tripledrug ART. However, in randomized clinical trials of HIV-1-infected adults on apparently effective ART, the addition of an integrase inhibitor (raltegravir) to stable regimens resulted in a transient increase in 2-LTR circles in some patients, suggesting a pre-intensification steady-state in which the processes of virion generation and de novo infection were occurring. Mathematical modeling of 2-LTR production during integrase inhibitor intensification suggests the coexistence, at different levels, of ongoing de novo infection and de novo replication mechanisms, specifically in inflamed lymphoid drug sanctuaries. Most reports looking into potential changes in 2-LTR circles in interventional clinical studies have simultaneously assessed other potential surrogate markers of viral persistence. Transient increases in 2-LTR circles have been correlated to decreases in $C D 8^{+} T$-cell activation, transient CD45RA- $C D 4^{+} \mathrm{T}$-cell redistribution, and decreases in the hypercoagulation biomarker D-dimer in ART-intensified individuals. It is difficult, however, to establish a systematic association because the level of correlation with different types of markers differs significantly among studies. In conclusion, despite suppressive ART, a steady-state of de novo infection may persist in some infected individuals and that this may drive immune activation and inflammation changes reflecting residual viral reservoir activity during otherwise apparently suppressive ART.
\end{abstract}

\section{The nature of episomal HIV DNA}

Integration into host-cell DNA is an essential step in the life cycle of all retroviruses, including HIV-1. Once integrated, the provirus is replicated as an integral element of the host genome, efficiently transcribing viral DNA into new copies of the viral genome and mRNAs that encode viral proteins [1]. Integration also is important to viral persistence. By integrating within host cell DNA, the virus essentially usurps the life span of the infected

\footnotetext{
*Correspondence: jmpicado@irsicaixa.es

${ }^{1}$ AIDS Research Institute IrsiCaixa, University Hospital Germans Trias i

Pujol, Ctra. de Canyet s/n, Badalona, 08916 Barcelona, Spain

Full list of author information is available at the end of the article
}

cell. Therefore, integration within long lived cells such as memory $\mathrm{CD} 4^{+} \mathrm{T}$ cells and macrophages contributes to HIV-1 persistence in the host. Furthermore, during mitosis, proviruses are duplicated in each daughter cell and thus homeostatic proliferation of infected cells provides an additional mechanism for proviral persistence [2-7].

Reverse transcription results in the generation of a linear cDNA that serves as the precursor to the integrated provirus. In addition, other classes of extrachromosomal viral cDNA molecules can be found in acutely infected cells including (1) 1-long terminal repeat (1-LTR) circle, which is most likely the result of homologous recombination between the LTRs of the linear DNA molecule; (2) 
2-LTR circles, whose structure is consistent with the ligation of the two ends of the linear precursor, often with deletions or insertions of a few nucleotides at the "circle junction" [1]. The 1-LTR and 2-LTR closed circular DNA are also referred as episomal HIV-1 DNA. However, unlike episomal DNA molecules of herpesviruses such as Epstein Barr Virus (EBV) that contain elements allowing autonomous episomal replication, episomes generated by HIV-1 cannot replicate autonomously.

Estimates of the efficiency with which newly synthesized viral cDNA molecules complete the subsequent steps leading to integration are technically difficult to obtain. However, under favorable in vitro conditions, between 10 and $30 \%$ of the viral cDNA molecules synthesized in acutely infected permissive cells will ultimately become integrated $[8,9]$. Therefore, unintegrated forms represent the largest fraction of HIV-1 cDNA in the nucleus. The suggested relative abundance is greater for unintegrated linear DNA followed by integrated provirus, 1-LTR circles $(\sim 10 \%)$, and finally 2 -LTR circles $(\sim 1 \%)$ [9-11]. Kinetically, they seem to appear in the same order [9]. While the linear molecule is the direct precursor to the integrated provirus, the circular forms appear to be dead-end by-products and do not serve as intermediates in the viral replication cycle. Since the free ends of linear viral DNA mimic double strand breaks of the chromosome and thus may provide a signal for apoptosis, circularization might be considered as a repair process to reduce such cellular danger signals [12]. Interestingly, recent data suggest that 2-LTR circles can also be used as a reserve supply of genomes for proviral integration [13]. However, this hypothesis has only been described in ex vivo experiments and its potential role in the overall HIV-1 replication cycle in vivo remains to be determined.

There are different PCR-based molecular methods for the specific detection and quantification of 2-LTR circles. A recent review has been devoted to precisely compare their properties and limitations [14]. The more recently developed digital droplet PCR (ddPCR) technology [15] is replacing conventional PCR methods $[16,17]$. Even if the relative abundance of unintegrated 1-LTR circles has been suggested to be tenfold greater than that of 2-LTR circles [9], methods for quantification of either 1-LTR circles or unintegrated viral linear DNA have only been developed in in vitro experiments [18], but not systematically applied to samples from clinical trials. As HIV-1 lacks necessary factors for the maintenance of episomal replication, it has been argued that these episomes are labile intermediates in the virus life cycle and as such, indicative of recent infection events [19]. However, the lability of 2-LTR circles has been questioned by in vitro experiments in some HIV-1-infected cell lines [20-22]. This specific aspect will be further discussed in the next sections.
It has been suggested that unintegrated HIV-1 DNA molecules can be transiently transcribed and perhaps even support virus production, latency and immune responses, especially during direct infection of resting $\mathrm{CD}^{+} \mathrm{T}$ cells [23-25]. Moreover, it has been shown that Nef expressed from extrachromosomal DNA, downregulates CD4 surface expression on primary $\mathrm{CD} 4^{+} \mathrm{T}$ lymphocytes, albeit not as efficiently as integrating virus [25, 26]. It is, however, uncertain whether the accumulation of unintegrated viral DNA might have a role in clinical pathogenesis. It has also been suggested that abundant unintegrated viral DNA is a manifestation of high-multiplicity of infection [27] that could occur during cellto-cell transmission in lymphoid tissues rather than in peripheral blood. This hypothesis would be compatible with the potential enrichment of 2-LTR circles in CD4 ${ }^{+}$ $\mathrm{T}$ lymphocytes migrating from tissues to peripheral blood [28, 29].

\section{Episomal HIV-1 DNA in the study of viral persistence during ART}

The existence of high levels of unintegrated HIV DNA in vivo was first demonstrated in blood and brain tissue of AIDS patients, with a maximum ratio of unintegrated to integrated HIV of approximately 80:1 [30]. It was also latter shown that during the asymptomatic phase of infection there was an extremely low total body load of latently infected resting $\mathrm{CD} 4^{+} \mathrm{T}$ cells with replication-competent integrated provirus. In treatment-naïve individuals, the most prevalent form of HIV-1 DNA in resting and activated $\mathrm{CD} 4^{+} \mathrm{T}$ cells is a full-length, linear, unintegrated form that is not replication competent [31].

The implementation after 1996 of combination antiretroviral therapy (ART) resulted in sustained suppression of viral replication in HIV-1-infected subjects. However, it was soon evident that a reservoir of latently infected cells established early in infection maintained viral persistence in the face of suppressive ART [31-33]. In this context, the detection of episomal HIV-1 DNA infection intermediates, specifically 2-LTR circles, in a large percentage of infected individuals on highly active ART, despite sustained undetectable levels of plasma viral RNA, was interpreted as suggesting that cells were still in the process of being infected [19]. Moreover, 2-LTR circles were preferentially observed in the effector memory $\mathrm{CD} 4^{+}$ T-cell subset compared to naive, memory stem cells, central-memory and terminally differentiated $\mathrm{CD} 4^{+} \mathrm{T}$ cell subsets of long-term treated subjects [34]. This suggests that in the context of potent cART, more differentiated/ activated cells are preferentially supporting new rounds of viral infection. The utility of 2-LTRs as indicators of an acute infection was questioned by in vitro experiments in some HIV-1-infected cell lines [20-22]. However, it 
was unclear whether such short-duration in vitro experiments in cell lines were predictive of episomal dynamics in vivo. To address whether 2-LTR episomes were labile in vivo, Sharkey et al. analyzed the dynamics of episomal cDNA turnover in vivo by following the emergence of an M184 $\mathrm{V}$ polymorphism in plasma viral RNA, in episomal cDNA, and in proviral DNA in patients on suboptimal therapies [35]. Acquisition of drug resistance in plasma resulted in a complete replacement of wild-type viral RNA genomes with genomes harboring the M184 V mutation within 2 weeks of treatment initiation. In the majority of individuals, episomes harboring the wild-type M184 codon had been replaced with episomes harboring a V184 codon within 6 weeks of treatment initiation. Importantly, a complete replacement of wild-type episomes with M184 V-containing episomes occurred while proviruses remained wild type over the 52-week duration of the study [35]. This study provided in vivo evidence that 2-LTRs are labile and dynamic. It is possible that the loss of wild-type episomes was due to turnover of the infected cell, but the time-scale of the turnover is faster than could be explained by the natural turnover of resting T-cell populations. Accelerated host cell turnover could be explained by viral cytopathicity and/or host immune mediated clearance. However, there is no evidence to suggest that cells harboring episomes are subject wither to viral cytopathicity or immune surveillance. Either process would require that episomes are sufficiently transcriptionally active to generate enough viral antigen that would promote cytopathicity and serve as an immune target. It is more likely that the rapid turnover observed for episomes reflected the lability of the episome and not the lability of the cell harboring it.

Even after the advent of newer antiretroviral drugs, the size of the latent reservoir in individuals in ART does not seem to change significantly after the first few years of treatment [34, 36, 37]. Therefore, researchers turned their attention on identifying approaches with which to gauge viral activity in individuals on effective ART as well as the impact of more potent antiviral regimens. Given the lack of any direct methods to quantify reservoir activity in vivo, we and others have used treatment intensifcation of standard regimens to determine if more potent ART can impact viral reservoir activity. With regard to residual plasma HIV-1 RNA, the results of these studies have been very consistent: adding a potent antiretroviral drug to a stable triple-drug regimen has no measurable impact on plasma HIV-1 RNA levels [38-45], suggesting that ongoing cycles of HIV-1 replication are not a major mechanism driving persistent plasma viremia during triple-drug ART.

The unique mechanism of action of the integrase inhibitor drug class allowed us, and others, to indirectly assess whether new rounds of infection could occur under suppressive ART. These drugs inhibit the integration of episomal HIV-1 DNA strands-including 2-LTR circles-into the host genome (Fig. 1). In two randomized clinical trials of HIV-1-infected adults on apparently effective ART, the addition of an integrase inhibitor (raltegravir) to a stable regimen resulted in a transient increase in 2-LTR circles. [46, 47]. An increase in episomal DNA with inhibition of integration suggests that at baseline (pre-intensification), there existed a steady-state in which the processes of virion generation and de novo infection were occurring despite the fact that all trial participants were fully suppressed on two reverse transcriptase inhibitors plus a protease inhibitor (PI) for the duration of the study. This phenomenon was observed in approximately $30 \%$ of subjects, with most of the activity observed in those who had been on a PI-based regimen. An acute increase in 2-LTR circles requires the presence of infectious virions and reverse transcription of a linear cDNA, which is the precursor for 2-LTR circles. Since virions and linear viral cDNAs are labile, de novo infection is necessary to drive increase in 2-LTRs upon raltegravir intensification. An important distinction needs to be made here. Recently produced infections virions may be produced by one of two pathways, either arising from pre-existing long-lived reservoir cells, or potentially from ongoing cycles of replication. Since either pathway will result in an increase in 2-LTR production following raltegravir intensification, an increase in 2-LTR circles following intensification only proves the existence of de novo infection, not necessarily de novo replication. However, as we will discuss later, the dynamics of 2-LTR following intensification do allow us to distinguish between these two pathways. Although the clinical significance of these events is unclear, it is evident that even under effective ART, there is some replenishment of infected cells by new rounds of infection.

\section{Mathematical modeling of episomal HIV DNA}

The intensification experiments discussed above shared several key characteristics that can guide modeling efforts. The patients had been on stable antiviral therapy with suppressed plasma viremia for extended periods prior to intensification, so it is reasonable to assume that the dynamics were at steady-state prior to the intensification. The administration of integrase inhibitor was sustained for the duration of the experiment, so the perturbation was monotonic (i.e., there were no complicated dynamics introduced by the perturbation itself). Finally, the response in the measured 2-LTR dynamics was characterized by a sharp increase followed by a gradual decrease, with the final concentration of 2-LTR episomes often below the baseline level. 


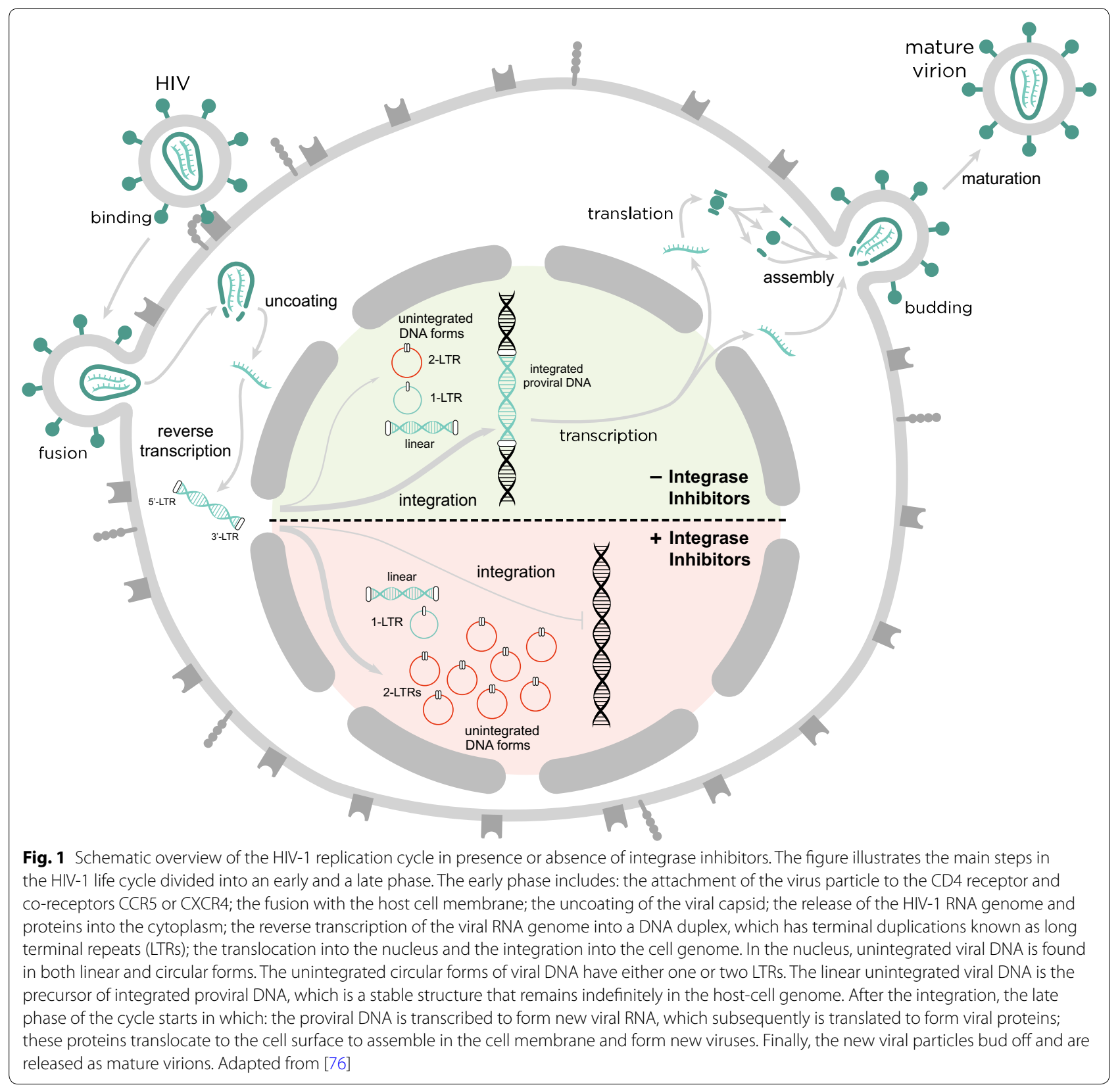

\section{Modeling 2-LTR production during integrase inhibitor intensification}

Integrase Inhibitors are known to promote the formation of 2-LTR episomes by blocking the activity of the integration complex, leaving the unintegrated linear HIV DNA as a target for the host DNA repair enzymes. The observed increase in 2-LTR is therefore best explained as the interruption of HIV integration events that would otherwise have occurred in the absence of integrase inhibitor. However, the presence of ongoing integration events does not necessarily imply the presence of ongoing rounds of replication, as there is a known pathway whereby quiescent infected cells may become active, produce virus, and create new infections that proceed to the integration phase without necessarily progressing to the virus-producing stage [48]. This is illustrated as pathway 1 in Fig. 2, which also shows the characteristic response in 2-LTR expected if pathway 1 dominates the source of the de novo infection events [49].

This pathway, however, is not capable of explaining the subsequent observed decrease in 2-LTR, integrase inhibitors have no suppressive effect on any step of this 


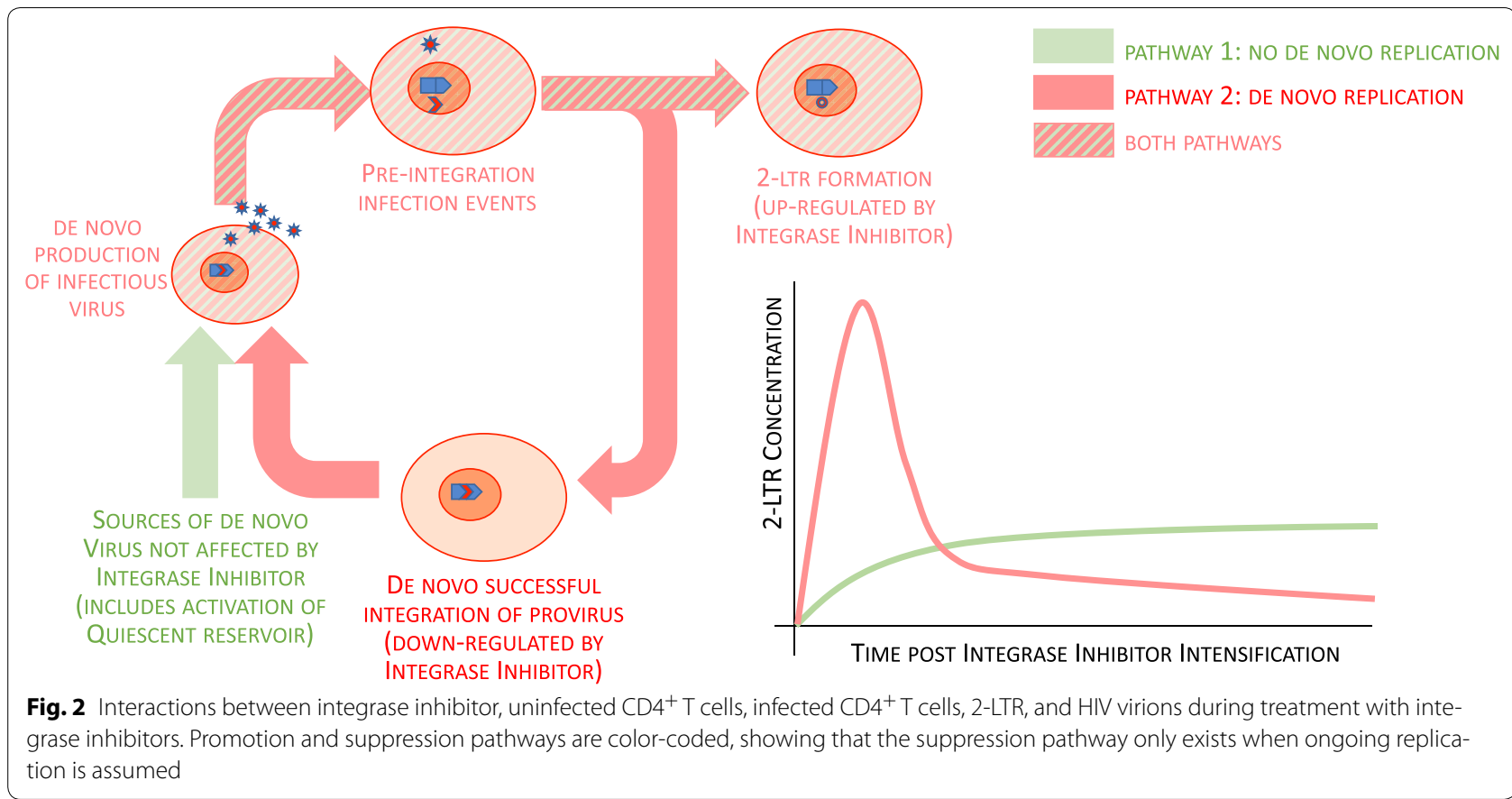

pathway (activation of quiescent infected cells, production of virus, viral entry and reverse transcription, formation of pre-integration complex). If we assume the presence of ongoing rounds of replication prior to intensification, illustrated (together with its characteristic response) in Fig. 2 as pathway 2, then a suppressive pathway exists where integrase inhibitor blocks the successful integration of HIV DNA, suppressing the population of virus-producing cells, suppressing the production of virus, cell entry, and formation of pre-integration complexes, and ultimately suppressing the production of 2-LTR episomes. An exhaustive search of possible monotone effect models $[50,51]$ has shown that only models that assume ongoing rounds of successful replication have suppressive pathways that are consistent with the known effects of integrase inhibitors [52]. The observed increase in 2-LTR following intensification, together with the subsequent decrease, can only be explained by the presence of successful rounds of HIV replication prior to intensification.

By fitting patient data to the model described above [49], we can determine how much of the virus involved in the de novo infection events was sourced from successful rounds of de novo replication, and how much came from sources unaffected by raltegravir intensification (including quiescent reservoir cells). We are also able to obtain estimates of the amount of viral replication prior to intensification necessary to produce the observed 2-LTR dynamics post-intensification. We have previously reported the simplest quantitative model capable of describing the 2-LTR behavior post-intensification [49]. This model tracked virus-producing infected cells, which may be created either by new infection events or by the activation of quiescent infected cells, and 2-LTR-containing cells.

The relatively sparse number of time points available mean than only the data from the Buzon trial $[43,46]$ had sufficient power to provide meaningful estimates of these rates, and even these estimates gave broad confidence intervals for most parameters. Interestingly, however, the estimates for the infection success ratios were very tightly constrained by the data, with seven of the patients in the study having this ratio bounded between 99 and $100 \%$. This means that almost all of the integration events occurring in these patients prior to intensification came from ongoing replication (pathway 2), with only a negligible amount coming from the activation of quiescent infected cells (pathway 1). By contrast, the other six patients with positive 2-LTR measurements following intensification did not have a tight constraint on the infection ratio, meaning that pathway 1 and pathway 2 explained the 2-LTR measurements equally well. The data from the Buzon trial [46] therefore provided evidence of at least ongoing de novo infection in $30 \%$ of the patients, and evidence of de novo replication in $15 \%$ of the patients. The amount of ongoing infection necessary to explain the data, while poorly constrained, was nevertheless quite high, with median estimates on the order of $10^{7}-10^{8}$ infected cells per day in the eight patients described. 


\section{Unchanging plasma viremia implies sanctuary-site origin of 2-LTR}

The high success ratios of viral infection found in the seven patients following intensification could not occur in the presence of suppressive levels of antiretrovirals. Furthermore, the levels of ongoing infection required to explain the observed 2-LTR dynamics in the thirteen patients would correspond to measurable level of plasma virus if it were evenly distributed through the body. Since plasma viral loads in the intensification trials remained below the standard limit of detection in all cases, it is necessary to assume that the 2-LTR formation (and the ongoing replication that produced it) are occurring in a site with nonsuppressive concentrations of antiretrovirals, sufficiently isolated from the blood that transport of free virus and actively infected cells are greatly reduced, but sufficiently connected to the blood that transport of 2-LTR-containing cells is possible. There is growing experimental evidence that many lymphoid tissues may serve as sanctuary sites $[53,54]$, with biopsy studies demonstrating non-suppressive levels of antiretrovirals in the lymphoid tissues of apparently suppressed patients. In fact, preliminary viral genetic analysis suggests that cells sequestered in tissues, rather than circulating $\mathrm{T}$ cells, might be responsible for supporting virus replication [28, 29].

In order to explore the feasibility of ongoing replication within a sanctuary site, we have developed a multi-compartment model of the sanctuary that captures the spatial effects characteristic of a lymphoid tissue-based drug sanctuary (Fig. 3), using infection dynamic rates and tissue transport rates derived from a number of human and animal studies. Analyzing this model leads to several interesting insights $[55,56]$. The model demonstrates that a lower limit in sanctuary size is necessary to sustain ongoing replication, even when no antiretrovirals are present. When the site is smaller than this size, target cells and infected cells are more likely to migrate through the site without interacting than remain in the site together long enough to interact. The number of infections occurring in the site under these circumstances is too low to be self-sustaining. A small site might explain increased levels of de novo infection, as per pathway 1 , but only a large site could sustain the de novo replication of pathway 2 . Based on the estimates used for T-cell transport rates, the minimum diameter for a sanctuary site to sustain ongoing replication is approximately $0.2 \mathrm{~mm}$. This is larger than the average size of a lymphoid follicle, but is consistent with the size of inflamed lymphoid follicles [57]. This shows that inflammation is a necessary condition for active replication in a sanctuary site. We would therefore expect signatures of ongoing replication in the 2-LTR dynamics post-intensification to correlate with markers of systemic inflammation pre-intensification.

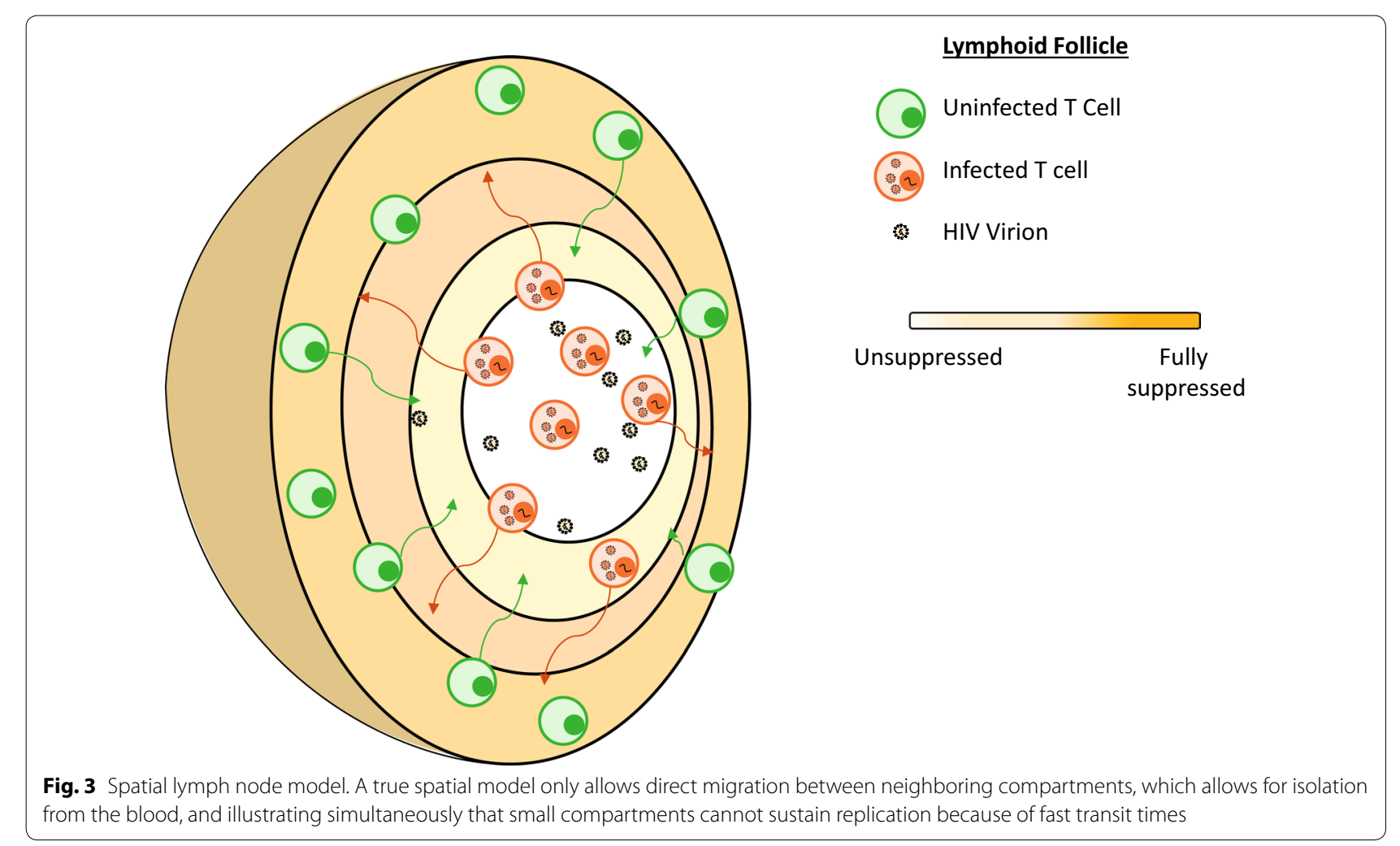


When multiple lymphoid sites with diameters larger than $0.2 \mathrm{~mm}$, a total dispersed site volume over $30 \mathrm{~mL}$, and sufficiently low antiviral activity are modeled, we find that ongoing infection rates as high as $10^{7}-10^{8}$ infected cells per day are consistent with no measurable change in the plasma virus level. When the addition of integrase inhibitor to these sites is simulated, the dynamics of 2-LTR formation in the site and their migration to the plasma produce curves identical to those seen in the data from the integrase inhibitor intensification trials. The mathematical models demonstrate that ongoing replication in inflamed lymphoid drug sanctuaries is a feasible explanation for the 2-LTR dynamics observed in seven patients following intensification. Recent data also suggest that HIV-1 actively evolves within lymph nodes due to low antiretroviral drug penetration in patients with undetectable levels of virus in their bloodstream [58], highlighting how dynamic and spatial processes act together to permit HIV-1 to persist within the infected host.

\section{Observed half-life of 2-LTR in the PBMCs is consistent with activated T-cell turnover}

The stability of 2-LTR episomes in vivo has been a subject of some controversy [19-22, 59, 60]. In vitro assays have shown the 2-LTR to be stable on short time scales, but in vivo studies have demonstrated 2-LTR dynamics consistent with a high turnover rate. In the model of sanctuary site dynamics described above, the 2-LTR in the intensification trial are formed in T cells in an environment of high inflammation, which will likely result in a high rate of T-cell activation and proliferation. The vast majority of activated T-cells during a proliferative immune response have short lifespans, with only a minority surviving to revert to long-lived memory cells [61]. The estimated half-life of the 2-LTR circles from these studies, when bias-corrected for the fact that measurements were made in the blood, not the sanctuary site [62], is fully consistent with the turnover rate of uninfected, activated, proliferating T-cells as estimated from patients with uncontrolled HIV infection [63, 64]. The observed 2-LTR turnover in this experiment can easily be explained either by native lability of the circles, or by the turnover rate of the host cells.

\section{Relationship to other markers of viral persistence}

One of the major problems for the research community that investigates HIV-1 persistence in subjects on suppressive ART ( $<50$ copies HIV-1 RNA/ml) is the precise quantification of viral reservoirs and potential residual levels of viral reservoir activity. The complexity is threefold: first, the very limited size of viral reservoirs that are sufficient to reset the infection if ART is withdrawn. Second, the multiplicity of assays to measure viral persistence; these range from replication competent virus to the simple presence of proviral DNA. While proviral DNA is a convenient and easy way to measure moiety (by for example droplet digital PCR), the majority of proviruses are archival and non-functional, and not likely to inform on the dynamic nature of the viral reservoir. Cell-associated viral RNA, cell-associated viral proteins, or inducible virus have also been used as surrogates for viral reservoir activity. Individually, these measurements do not provide comprehensive insight into viral reservoir size or activity and as such, multiple surrogates are normally included in studies of viral persistence. Because HIV-1 infection is inevitably linked to increases in cellular activation and inflammation, other immune-based markers are systematically considered, even in the settings of controlled plasma viremia, including levels of $\mathrm{T}$-cell activation in total $\mathrm{CD} 4^{+} \mathrm{T}$ cells or specific subpopulations, as well as plasma biomarkers of inflammation (CRP, IL-6), coagulation (D-Dimer) and bacterial translocation (sCD14). And third, the challenge in understanding viral persistence in peripheral blood and tissues, especially lymphoid-associated tissues where the majority of the principal cell target for HIV-1, the $\mathrm{CD}^{+}{ }^{+} \mathrm{T}$ lymphocytes, reside.

As a consequence, most of the reports looking into potential changes in 2-LTR circles in interventional clinical studies have simultaneously assessed other potential surrogate markers of viral persistence. It is difficult, however, to establish a systematic association between them, because the type of markers differs significantly among studies.

Our first prospective, open-label, randomized study comprising 69 individuals on suppressive triple-drug antiretroviral treatment that were randomly assigned 2:1 to receive raltegravir intensification over 48 weeks, resulted in a specific and transient increase in episomal DNAs in approximately $30 \%$ of the study participants. In subjects exhibiting an elevation in episomal DNAs, immune activation was higher at baseline and was subsequently normalized after raltegravir intensification [43, 46]. Subsequent raltegravir discontinuation for 12 weeks resulted in a partial rebound in CD8 activation markers in the 2-LTR+ subgroup, restoring the differences between subgroups observed at study entry, particularly in terms of CD38 expression within the CD8 memory T-cell compartment [65]. An association was also found between reductions in immune activation and plasma levels of D-dimer (a coagulation biomarker that is predictive of morbidity and mortality among patients receiving treatment for HIV-1 infection), which exclusively decreased in intensified patients on PI-based ART regimens, highlighting the link between ART composition and residual de novo viral infection [66]. Conversely, the 
perturbation in 2-LTR circles during raltegravir intensification was not associated with detectable changes in total or integrated HIV-1 DNA in peripheral PBMCs, residual plasma viremia, $\mathrm{CD}^{+}$and $\mathrm{CD} 8^{+} \mathrm{T}$-cell populations in blood, nor with multiple biomarkers of inflammation in plasma, including sCD14 $[43,46,66]$.

A similarly designed study included 31 subjects on suppressive triple-drug antiretroviral treatment. Raltegravir intensification for 24 weeks also resulted in a transient increase in 2-LTR circles, which was also associated with a slight but significant decrease in the $\mathrm{D}$-dimer level in plasma [47]. No differences were however found for residual plasma viremia, total HIV DNA in peripheral PBMCs, $\mathrm{CD}^{+}$and $\mathrm{CD}^{+}{ }^{+} \mathrm{T}$-cell populations or their activation levels in blood, as neither in IL-6, a biomarker of inflammation in plasma [47].

Alternative studies have shown no effect of raltegravir intensification on viral replication markers in the blood of HIV-1-infected patients receiving ART, including 2-LTR circles [40]. Nevertheless, the transient increase in 2-LTR circles in this study might have been missed as the first sample was taken 12 weeks after intensification. In any case, 12 out of 50 subjects had detectable 2-LTR circles at baseline, in association with higher residual plasma viremia and higher total HIV-1 DNA in $\mathrm{CD}_{4}^{+} \mathrm{T}$ cells [40]. Similarly, nine chronically HIV-1-infected subjects on stable ART intensified their therapy with raltegravir in a non-comparative pilot trial, with no significant shortterm effect on a qualitative measure of 2-LTR circles [45].

Another prospective, open-label, randomized study, comprising 30 individuals, evaluated the effect of adding maraviroc to a raltegravir-based regimen in early HIV-1 infection for 24 weeks [67]. There was again a transient increase in 2-LTR circles in both groups early after initiation of treatment, which decreased earlier in maraviroctreated individuals. Residual plasma viremia, absolute $\mathrm{CD}^{+}{ }^{+} \mathrm{T}$-cell and $\mathrm{CD} 8^{+} \mathrm{T}$-cell counts, immune activation, $\mathrm{CD} 4^{+} / \mathrm{CD}^{+} \mathrm{T}$-cell ratio, and soluble inflammation biomarkers (D-dimer, CRP, sCD14, Lp-PLA2, sVCAM1 , and IL-6) were similar in both arms at the end of the study [67].

Early studies in HIV-infected individuals who initiated ART reported conflicting information. While one study suggested that the 2-LTR circles in a subgroup of patients rapidly decayed following initiation of suppressive ART [68], other suggested a low impact of ART on 2-LTR circle levels in vivo despite significant changes in plasma viremia and infectious cell frequency [59]. Short-term antiretroviral treatment interruptions showed a profound correlation between levels of total HIV-1 DNA and unintegrated episomal DNA, but treatment discontinuation for only 15 days, followed by treatment resumption, did not alter any of these two parameters [69].
Outside of the context of interventional clinical trials, the level of 2-LTR circles has been compared with other measures of viral reservoirs in HIV-1 eradication studies. Detection and quantitation of 2-LTR circular DNA was shown to correlate with the frequency of the recovery of replication-competent virus from PBMC obtained from effectively treated patients [70]. More recently, 2-LTR circles in PBMCs or resting $\mathrm{CD} 4^{+} \mathrm{T}$ cells were shown not to correlate with infected cell frequencies measured in the viral outgrowth assay either in acute or chronically infected subjects [71]. The geometric mean level of 2-LTR circles was 27-fold and 34-fold lower than the total level of HIV-1 DNA measured in PBMC and purified resting $\mathrm{CD}^{+} \mathrm{T}$ cells respectively [71]. Another report found lower levels of episomal 2-LTR circles in peripheral PBMCs of ART-treated patients (either early infected or chronically infected) and LTNPs, compared to recent ART-naïve seroconverters [72]. However, this study found no correlation between 2-LTR circles and HIV-1 usRNA, total or integrated HIV-1 DNA, or the $\mathrm{CD} 4 / \mathrm{CD} 8$ ratio. It has been also found that 2-LTR circles are much more common in the PBMC of elite suppressors compared to other HIV-1 infected individuals, either treated or untreated [73]. Coincidentally, elite suppressors in this study had lower levels of integrated HIV-1 DNA than other HIV-1 infected individuals, which has also been observed in later reports [34]. However, no formal correlation between the levels of 2-LTR circles and integrated HIV-1 DNA was attempted [73].

These results suggest that, despite suppressive ART, a steady state of de novo infection may persist in some infected individuals and that this may drive immune activation. The decrease in $\mathrm{CD}^{+}{ }^{+}$-cell activation, a transient $\mathrm{CD}_{45 \mathrm{RA}^{-}} \mathrm{CD}^{+}{ }^{+} \mathrm{T}$-cell redistribution, and decreases in the hypercoagulation biomarker D-dimer in intensified individuals may reflect residual viral reservoir activity during otherwise apparently suppressive ART.

\section{Clinical implications}

There is still significant controversy regarding to what extent either single or multiple markers of viral persistence can provide clinically meaningful information. Suggested interventions to reduce the level of viral reservoirs, residual viral replication or low-level viral replication do not necessarily translate into actual clinical benefit.

In the context of theoretically suppressive HIV-1 therapies, antiretroviral regimens based on PI might be less able to achieve the same level of viral suppression as suggested by the more frequent transient increase in 2-LTR circles when triple-drug therapies are intensified with raltegravir [46, 47]. However, the sole virologic success rates of subjects with continued virologic suppression 
under triple-drug suppressive regimens based on PI does not seem to be different from patients on other regimens.

Raltegravir, as the first clinically available integrase inhibitor, has been exhaustively explored in its potential to contribute to HIV-1 cure strategies. Elvitegravir and dolutegravir are running a little bit behind in such exploratory studies. Newer, still in-development antiretroviral drugs will potentially add novel possibilities to the design of HIV-1 eradication strategies. Such strategies will have to prove their efficacy not only in peripheral blood but also in multiple lymphoid tissues throughout the body where the vast majority of target cells for HIV-1 reside. In this regard, new methodologies that could allow the quantification of markers of viral persistence in intact lymphoid cells obtained from less accessible tissues might play a pivotal role $[74,75]$. In fact, the specific detection of 2-LTR circles in tissue-resident lymphoid cells has not yet been reported, either in a descriptive way or in the setting of an interventional strategy to reduce viral persistence in otherwise well-treated individuals.

\section{Authors' contributions}

$J M-P, R Z, M J B, M S$ contributed equally to this manuscript. All authors read and approved the final manuscript.

\section{Author details \\ ${ }^{1}$ AIDS Research Institute IrsiCaixa, University Hospital Germans Trias i Pujol, Ctra. de Canyet s/n, Badalona, 08916 Barcelona, Spain. ${ }^{2}$ University of Vic-Central University of Catalonia (UVic-UCC), Vic, Spain. ${ }^{3}$ Catalan Institution for Research and Advanced Studies (ICREA), Barcelona, Spain. ${ }^{4}$ Department of Biomedical Engineering, University of Delaware, Newark, DE, USA. ${ }^{5}$ Infectious Diseases Department, Vall d'Hebron Research Institute, Hospital Universitari Vall d'Hebron, Barcelona, Spain. ${ }^{6}$ Division of Infectious Diseases, Department of Medicine, University of Miami Miller School of Medicine, Miami, FL, USA.}

\section{Acknowledgements}

We thank S. Morón-López and M. Salgado for expert assistance with the figures preparation. J.M.P. group is supported by the Spanish Secretariat for Research through Grants SAF2016-80033-R and RTC-2016-5324-1, the European Commission under the FP7 program (Project HEALTH-602570), and the Foundation for AIDS Research amfAR (109552-61-RSRL). R.Z. group is supported in part by the National Institutes of Health (NIH) through Grant Al1 1028. M.J.B. group is supported by the NIH through Grant R21Al1 18411, the Spanish Secretariat of Science and Innovation and FEDER funds (Grant SAF2015-67334-R), the Spanish AIDS network "Red Temática Cooperativa de Investigación en SIDA" (RD16/0025/0007) and GeSIDA. MJB holds a Miguel Servet contract (CP17/00142) funded by the Spanish Health Institute Carlos III. MS group is supported in part by the NIH through Grants 12065631, 096109 and 093306.

\section{Competing interests}

M.P. group is partially supported by unrestricted grant support from Gilead, Merck Sharp and Dohme, and ViiV Healthcare. R.Z. group has previously received unrestricted grant support from Merck Sharp and Dohme. M.J.B. group is partially supported by unrestricted grant support from Bristol-Myers Squibb. The funders had no role in the preparation of this manuscript. R.Z. is named on a US patent application related to this work.

\section{Ethics approval and consent to participate} Not applicable.

\section{Publisher's Note}

Springer Nature remains neutral with regard to jurisdictional claims in published maps and institutional affiliations.
Received: 9 October 2017 Accepted: 19 January 2018

Published online: 30 January 2018

\section{References}

1. Coffin JM, Hughes SH, Varmus H. Retroviruses. Plainview: Cold Spring Harbor Laboratory Press; 1997

2. Chomont N, El-Far M, Ancuta P, Trautmann L, Procopio FA, Yassine-Diab B, Boucher G, Boulassel MR, Ghattas G, Brenchley JM, Schacker TW, Hill BJ, Douek DC, Routy JP, Haddad EK, Sékaly RP. HIV reservoir size and persistence are driven by $T$ cell survival and homeostatic proliferation. Nat Med. 2009:15:893-900

3. Cohn LB, Silva IT, Oliveira TY, Rosales RA, Parrish EH, Learn GH, Hahn BH, Czartoski JL, McElrath MJ, Lehmann C, Klein F, Caskey M, Walker BD, Siliciano JD, Siliciano RF, Jankovic M, Nussenzweig MC. HIV-1 integration landscape during latent and active infection. Cell. 2015;160:420-32.

4. Maldarelli F, Wu X, Su L, Simonetti FR, Shao W, Hill S, Spindler J, Ferris AL, Mellors JW, Kearney MF, Coffin JM, Hughes SH. HIV latency. Specific HIV integration sites are linked to clonal expansion and persistence of infected cells. Science. 2014;345:179-83.

5. Simonetti FR, Sobolewski MD, Fyne E, Shao W, Spindler J, Hattori J, Anderson EM, Watters SA, Hill S, Wu X, Wells D, Su L, Luke BT, Halvas EK, Besson G, Penrose KJ, Yang Z, Kwan RW, Van Waes C, UldrickT, Citrin DE, Kovacs J, Polis MA, Rehm CA, Gorelick R, Piatak M, Keele BF, Kearney MF, Coffin JM, Hughes SH, Mellors JW, Maldarelli F. Clonally expanded CD4 ${ }^{+}$ T cells can produce infectious HIV-1 in vivo. Proc Natl Acad Sci USA. 2016;113:1883-8.

6. von Stockenstrom S, Odevall L, Lee E, Sinclair E, Bacchetti P, Killian M, Epling L, Shao W, Hoh R, Ho T, Faria NR, Lemey P, Albert J, Hunt P, Loeb L, Pilcher C, Poole L, Hatano H, Somsouk M, Douek D, Boritz E, Deeks SG, Hecht FM, Palmer S. Longitudinal genetic characterization reveals that cell proliferation maintains a persistent HIV Type 1 DNA pool during effective HIV therapy. J Infect Dis. 2015;212:596-607.

7. Wagner TA, McLaughlin S, Garg K, Cheung CY, Larsen BB, Styrchak S, Huang HC, Edlefsen PT, Mullins JI, Frenkel LM. HIV latency. Proliferation of cells with HIV integrated into cancer genes contributes to persistent infection. Science. 2014;345:570-3.

8. Barbosa P, Charneau P, Dumey N, Clavel F. Kinetic analysis of HIV-1 early replicative steps in a coculture system. AIDS Res Hum Retroviruses. 1994;10:53-9.

9. Meyerhans A, Breinig T, Vartanian J-P, Wain-Hobson S. Forms and function of intracellular HIV DNA. HIV Seq Compend. 2003;2004:14.

10. Butler SL, Hansen MS, Bushman FD. A quantitative assay for HIV DNA integration in vivo. Nat Med. 2001;7:631-4.

11. Vandegraaff N, Kumar R, Burrell CJ, Li P. Kinetics of human immunodeficiency virus type 1 (HIV) DNA integration in acutely infected cells as determined using a novel assay for detection of integrated HIV DNA.J Virol. 2001;75:11253-60.

12. Li L, Olvera JM, Yoder KE, Mitchell RS, Butler SL, Lieber M, Martin SL, Bushman FD. Role of the non-homologous DNA end joining pathway in the early steps of retroviral infection. EMBO J. 2001;20:3272-81.

13. Thierry S, Munir S, Thierry E, Subra F, Leh H, Zamborlini A, Saenz D, Levy DN, Lesbats P, Saïb A, Parissi V, Poeschla E, Deprez E, Delelis O. Integrase inhibitor reversal dynamics indicate unintegrated HIV-1 DNA initiate de novo integration. Retrovirology. 2015;12:24.

14. Olivares I, Pernas M, Casado C, López-Galindez C. Human immunodeficiency virus type 1 two-long terminal repeat circles: a subject for debate. AIDS Rev. 2016;18:23-31.

15. Strain MC, Lada SM, Luong T, Rought SE, Gianella S, Terry VH, Spina CA, Woelk CH, Richman DD. Highly precise measurement of HIV DNA by droplet digital PCR. PLoS ONE. 2013;8:e55943.

16. Stevenson M, Haggerty S, Lamonica CA, Meier CM, Welch SK, Wasiak AJ. Integration is not necessary for expression of human immunodeficiency virus type 1 protein products. JVirol. 1990;64:2421-5.

17. Murray JM, Zaunders JJ, McBride KL, Xu Y, Bailey M, Suzuki K, Cooper DA, Emery S, Kelleher AD, Koelsch KK. PINT Study Team: HIV DNA subspecies persist in both activated and resting memory $\mathrm{CD}^{+} \mathrm{T}$ cells during antiretroviral therapy. J Virol. 2014;88:3516-26. 
18. Munir S, Thierry S, Subra F, Deprez E, Delelis O. Quantitative analysis of the time-course of viral DNA forms during the HIV-1 life cycle. Retrovirology. 2013;10:87.

19. Sharkey ME, Teo I, Greenough T, Sharova N, Luzuriaga K, Sullivan JL, Bucy RP, Kostrikis LG, Haase A, Veryard C, Davaro RE, Cheeseman SH, Daly JS, Bova C, Ellison RT, Mady B, Lai KK, Moyle G, Nelson M, Gazzard B, Shaunak S, Stevenson M. Persistence of episomal HIV-1 infection intermediates in patients on highly active anti-retroviral therapy. Nat Med. 2000;6:76-81.

20. Butler SL, Johnson EP, Bushman FD. Human immunodeficiency virus cDNA metabolism: notable stability of two-long terminal repeat circles. J Virol. 2002;76:3739-47.

21. Pierson TC, Kieffer TL, Ruff CT, Buck C, Gange SJ, Siliciano RF. Intrinsic stability of episomal circles formed during human immunodeficiency virus type 1 replication. J Virol. 2002;76:4138-44.

22. Pace MJ, Graf EH, O'Doherty U. HIV 2-long terminal repeat circular DNA is stable in primary CD4+ ${ }^{+}$Cells. Virology. 2013;441:18-21.

23. Engelman A, Englund G, Orenstein JM, Martin MA, Craigie R. Multiple effects of mutations in human immunodeficiency virus type 1 integrase on viral replication. J Virol. 1995;69:2729-36.

24. Wiskerchen M, Muesing MA. Human immunodeficiency virus type 1 integrase: effects of mutations on viral ability to integrate, direct viral gene expression from unintegrated viral DNA templates, and sustain viral propagation in primary cells. J Virol. 1995;69:376-86.

25. Chan CN, Trinité B, Lee CS, Mahajan S, Anand A, Wodarz D, Sabbaj S, Bansal A, Goepfert PA, Levy DN. HIV-1 latency and virus production from unintegrated genomes following direct infection of resting CD4T cells. Retrovirology. 2016;13:1.

26. Gillim-Ross L, Cara A, Klotman ME. Nef expressed from human immunodeficiency virus type 1 extrachromosomal DNA downregulates CD4 on primary CD4 $4^{+}$T lymphocytes: implications for integrase inhibitors. J Gen Virol. 2005;86:765-71.

27. Bergeron L, Sodroski J. Dissociation of unintegrated viral DNA accumulation from single-cell lysis induced by human immunodeficiency virus type 1. J Virol. 1992;66:5777-87.

28. Puertas MC, Noguera-Julian M, Massanella M, Pou C, Buzon MJ, Clotet B, Stevenson M, Paredes R, Blanco J, Martinez-Picado J. Lack of concordance between residual viremia and viral variants driving de novo infection of CD4(+) T cells on ART. Retrovirology. 2016;13:51.

29. Buzón MJ, Codoñer FM, Frost SD, Pou C, Puertas MC, Massanella M, Dalmau J, Llibre JM, Stevenson M, Blanco J, Clotet B, Paredes R, MartinezPicado J. Deep molecular characterization of HIV-1 dynamics under suppressive HAART. PLoS Pathog. 2011;7:e1002314.

30. Pang S, Koyanagi Y, Miles S, Wiley C, Vinters HV, Chen IS. High levels of unintegrated HIV-1 DNA in brain tissue of AIDS dementia patients. Nature. 1990;343:85-9.

31. Chun TW, Carruth L, Finzi D, Shen X, DiGiuseppe JA, Taylor H, Hermankova M, Chadwick K, Margolick J, Quinn TC, Kuo YH, Brookmeyer R, Zeiger MA, Barditch-Crovo P, Siliciano RF. Quantification of latent tissue reservoirs and total body viral load in HIV-1 infection. Nature. 1997;387:183-8.

32. Finzi $D$, Hermankova M, Pierson $T$, Carruth LM, Buck C, Chaisson RE, Quinn TC, Chadwick K, Margolick J, Brookmeyer R, Gallant J, Markowitz M, Ho DD, Richman DD, Siliciano RF. Identification of a reservoir for HIV-1 in patients on highly active antiretroviral therapy. Science. 1997;278:1295-300.

33. Wong JK, Hezareh M, Günthard HF, Havlir DV, Ignacio CC, Spina CA, Richman DD. Recovery of replication-competent HIV despite prolonged suppression of plasma viremia. Science. 1997;278:1291-5.

34. Buzon MJ, Martin-Gayo E, Pereyra F, Ouyang Z, Sun H, Li JZ, Piovoso M, Shaw A, Dalmau J, Zangger N, Martinez-Picado J, Zurakowski R, Yu XG, Telenti A, Walker BD, Rosenberg ES, Lichterfeld M. Long-term antiretroviral treatment initiated at primary HIV-1 infection affects the size, composition, and decay kinetics of the reservoir of HIV-1-infected CD4T cells. J Virol. 2014;88:10056-65.

35. Sharkey M, Triques K, Kuritzkes DR, Stevenson M. In vivo evidence for instability of episomal human immunodeficiency virus type 1 cDNA. J Virol. 2005;79:5203-10.

36. Besson GJ, McMahon D, Maldarelli F, Mellors JW. Short-course raltegravir intensification does not increase 2 long terminal repeat episomal HIV-1 DNA in patients on effective antiretroviral therapy. Clin Infect Dis. 2012:54:451-3.
37. Crooks AM, Bateson R, Cope AB, Dahl NP, Griggs MK, Kuruc JD, Gay CL, Eron JJ, Margolis DM, Bosch RJ, Archin NM. Precise quantitation of the latent HIV-1 reservoir: implications for eradication strategies. J Infect Dis. 2015;212:1361-5

38. Byakwaga H, Kelly M, Purcell DF, French MA, Amin J, Lewin SR, Haskelberg H, Kelleher AD, Garsia R, Boyd MA, Cooper DA, Emery S. CORAL Study Group: intensification of antiretroviral therapy with raltegravir or addition of hyperimmune bovine colostrum in HIV-infected patients with suboptimal CD4 ${ }^{+}$T-cell response: a randomized controlled trial. J Infect Dis. 2011;204:1532-40.

39. Dinoso JB, Kim SY, Wiegand AM, Palmer SE, Gange SJ, Cranmer L, O'Shea A, Callender M, Spivak A, Brennan T, Kearney MF, Proschan MA, Mican JM, Rehm CA, Coffin JM, Mellors JW, Siliciano RF, Maldarelli F. Treatment intensification does not reduce residual HIV-1 viremia in patients on highly active antiretroviral therapy. Proc Natl Acad Sci USA. 2009;106:9403-8.

40. Gandhi RT, Coombs RW, Chan ES, Bosch RJ, Zheng L, Margolis DM, Read S, Kallungal B, Chang M, Goecker EA, Wiegand A, Kearney M, Jacobson JM, D'Aquila R, Lederman MM, Mellors JW, Eron JJ. AIDS Clinical Trials Group (ACTG) A5244 Team: no effect of raltegravir intensification on viral replication markers in the blood of HIV-1-infected patients receiving antiretroviral therapy. J Acquir Immune Defic Syndr. 2012;59:229-35.

41. Hatano H, Hayes TL, DahI V, Sinclair E, Lee T, Hoh R, Lampiris H, Hunt PW, Palmer S, McCune JM, Martin JN, Busch MP, Shacklett BL, Deeks SG. A randomized, controlled trial of raltegravir intensification in antiretroviraltreated, HIV-infected patients with a suboptimal $C D 4^{+} \mathrm{T}$ cell response. J Infect Dis. 2011;203:960-8.

42. Hunt PW, Shulman NS, Hayes TL, Dahl V, Somsouk M, Funderburg NT, McLaughlin B, Landay AL, Adeyemi O, Gilman LE, Clagett B, Rodriguez B, Martin JN, Schacker TW, Shacklett BL, Palmer S, Lederman MM, Deeks SG. The immunologic effects of maraviroc intensification in treated HIVinfected individuals with incomplete $\mathrm{CD} 4^{+} \mathrm{T}$-cell recovery: a randomized trial. Blood. 2013;121:4635-46.

43. Llibre JM, Buzón MJ, Massanella M, Esteve A, DahIV, Puertas MC Domingo P, Gatell JM, Larrouse M, Gutierrez M, Palmer S, Stevenson M, Blanco J, Martinez-Picado J, Clotet B. Treatment intensification with raltegravir in subjects with sustained HIV-1 viraemia suppression: a randomized 48-week study. Antivir Ther. 2012;17:355-64.

44. McMahon D, Jones J, Wiegand A, Gange SJ, Kearney M, Palmer S, McNulty S, Metcalf JA, Acosta E, Rehm C, Coffin JM, Mellors JW, Maldarelli F. Shortcourse raltegravir intensification does not reduce persistent low-level viremia in patients with HIV-1 suppression during receipt of combination antiretroviral therapy. Clin Infect Dis. 2010;50:912-9.

45. Vallejo A, Gutierrez C, Hernandez-Novoa B, Diaz L, Madrid N, AbadFernandez M, Dronda F, Perez-Elias MJ, Zamora J, Muñoz E, MuñozFernandez MA, Moreno S. The effect of intensification with raltegravir on the HIV-1 reservoir of latently infected memory CD4 T cells in suppressed patients. AIDS. 2012;26:1885-94.

46. Buzón MJ, Massanella M, Llibre JM, Esteve A, DahI V, Puertas MC, Gatell JM, Domingo P, Paredes R, Sharkey M, Palmer S, Stevenson M, Clotet B, Blanco J, Martinez-Picado J. HIV-1 replication and immune dynamics are affected by raltegravir intensification of HAART-suppressed subjects. Nat Med. 2010;16:460-5.

47. Hatano H, Strain MC, Scherzer R, Bacchetti P, Wentworth D, Hoh R, Martin JN, McCune JM, Neaton JD, Tracy RP, Hsue PY, Richman DD, Deeks SG. Increase in 2-long terminal repeat circles and decrease in D-dimer after raltegravir intensification in patients with treated HIV infection: a randomized, placebo-controlled trial. J Infect Dis. 2013;208:1436-42.

48. Eisele E, Siliciano RF. Redefining the viral reservoirs that prevent HIV-1 eradication. Immunity. 2012;37:377-88.

49. Luo R, Cardozo EF, Piovoso MJ, Wu H, Buzon MJ, Martinez-Picado J, Zurakowski R. Modelling HIV-1 2-LTR dynamics following raltegravir intensification. J R Soc Interface. 2013;10:20130186.

50. Angeli D, Sontag ED. Monotone control systems. IEEE Trans Autom Control. 2003:48:1684-98.

51. Angeli D, Sontag ED. Remarks on the invalidation of biological models using monotone systems theory. In: 2012 IEEE 51st annual conference on decision and control (CDC) 2012. p. 2989-94.

52. Piovoso MJ, Zurakowski R. Evaluation of HIV 2-LTR formation models using monotone system theory. In: American control conference (ACC), 2014; 2014. p. 2747-52. 
53. Fletcher CV, Staskus K, Wietgrefe SW, Rothenberger M, Reilly C, Chipman JG, Beilman GJ, Khoruts A, Thorkelson A, Schmidt TE, Anderson J, Perkey K, Stevenson M, Perelson AS, Douek DC, Haase AT, Schacker TW. Persistent HIV-1 replication is associated with lower antiretroviral drug concentrations in lymphatic tissues. Proc Natl Acad Sci USA. 2014;111:2307-12.

54. Fukazawa Y, Lum R, Okoye AA, Park H, Matsuda K, Bae JY, Hagen SI, Shoemaker R, Deleage C, Lucero C, Morcock D, Swanson T, Legasse AW, Axthelm MK, Hesselgesser J, Geleziunas R, Hirsch VM, Edlefsen PT, Piatak M, Estes JD, Lifson JD, Picker $L$. B cell follicle sanctuary permits persistent productive simian immunodeficiency virus infection in elite controllers. Nat Med. 2015:21:132-9.

55. Cardozo EF, Luo R, Piovoso MJ, Zurakowski R. Spatial modeling of HIV cryptic viremia and 2-LTR formation during raltegravir intensification. J Theor Biol. 2014;345:61-9.

56. Cardozo EF, Piovoso MJ, Zurakowski R. Increased inflammation in sanctuary sites may explain viral blips in HIV infection. IET Syst Biol. 2016;10:153-66.

57. Alòs L, Navarrete P, Morente V, Garcia F, Garrido M, Plana M, Mozos A, López A, Gil C, Pumarola T, Caballero M, Blanch JL, Fumero E, Miró JM, Gallart T, Gatell JM, Campo E. Immunoarchitecture of lymphoid tissue in HIVinfection during antiretroviral therapy correlates with viral persistence. Mod Pathol. 2005;18:127-36.

58. Lorenzo-Redondo R, Fryer HR, Bedford T, Kim EY, Archer J, Pond SLK, Chung YS, Penugonda S, Chipman J, Fletcher CV, Schacker TW, Malim MH, Rambaut A, Haase AT, McLean AR, Wolinsky SM. Persistent HIV-1 replication maintains the tissue reservoir during therapy. Nature. 2016;530:51-6.

59. Brussel A, Mathez D, Broche-Pierre S, Lancar R, Calvez T, Sonigo P, Leibowitch J. Longitudinal monitoring of 2-long terminal repeat circles in peripheral blood mononuclear cells from patients with chronic HIV-1 infection. AIDS. 2003;17:645-52.

60. Clarke S, Almond N, Berry N. Simian immunodeficiency virus Nef gene regulates the production of 2-LTR circles in vivo. Virology. 2003;306:100-8.

61. De Boer RJ, Perelson AS. Quantifying T lymphocyte turnover. J Theor Biol. 2013;327:45-87.

62. Cardozo EF, Zurakowski R, Attoh-Okine N. Analysis of HIV-1 compartmental model parameters using Bayesian MCMC estimation. In: American control conference (ACC), 2014; 2014. P. 2765-70.

63. Luo R, Piovoso MJ, Martinez-Picado J, Zurakowski R. HIV model parameter estimates from interruption trial data including drug efficacy and reservoir dynamics. PLoS ONE. 2012;7:e40198.

64. Huang Y, Wu H, Acosta EP. Hierarchical Bayesian inference for HIV dynamic differential equation models incorporating multiple treatment factors. Biom J. 2010;52:470-86.

65. Massanella M, Esteve A, Buzón MJ, Llibre JM, Puertas MC, Gatell JM, Domingo P, Stevenson M, Clotet B, Martinez-Picado J, Blanco J. IntegRal Collaborative Group: dynamics of CD8 T-cell activation after discontinuation of HIV treatment intensification. J Acquir Immune Defic Syndr. 2013;63:152-60

66. Massanella M, Ouchi D, Marfil S, Llibre JM, Puertas MC, Buzón MJ, Richman DD, Orna E, Stevenson M, Gatell JM, Domingo P, Negredo E, Martinez-Picado J, Clotet B, Blanco J. Different plasma markers of inflammation are influenced by immune recovery and CART composition or intensification in treated HIV infected individuals. PLOS ONE. 2014:9:e114142.

67. Puertas MC, Massanella M, Llibre JM, Ballestero M, Buzon MJ, Ouchi D, Esteve A, Boix J, Manzardo C, Miró JM, Gatell JM, Clotet B, Blanco J, Martinez-Picado J. MaraviBoost Collaborative Group: intensification of a raltegravir-based regimen with maraviroc in early HIV-1 infection. AIDS. 2014;28:325-34.

68. Morlese J, Teo IA, Choi JW, Gazzard B, Shaunak S. Identification of two mutually exclusive groups after long-term monitoring of HIV DNA 2-LTR circle copy number in patients on HAART. AIDS. 2003;17:679-83.

69. Fischer M, Trkola A, Joos B, Hafner R, Joller H, Muesing MA, Kaufman DR, Berli E, Hirschel B, Weber R, Günthard HF. Swiss HIV-1 Cohort Study: shifts in cell-associated HIV-1 RNA but not in episomal HIV-1 DNA correlate with new cycles of HIV-1 infection in vivo. Antivir Ther. 2003;8:97-104.

70. Dornadula G, Nunnari G, Vanella M, Roman J, Babinchak T, DeSimone J, Stern J, Braffman M, Zhang H, Pomerantz RJ. Human immunodeficiency virus type 1-infected persons with residual disease and virus reservoirs on suppressive highly active antiretroviral therapy can be stratified into relevant virologic and immunologic subgroups. J Infect Dis. 2001;183:1682-7.

71. Eriksson S, Graf EH, Dahl V, Strain MC, YukI SA, Lysenko ES, Bosch RJ, Lai J, Chioma S, Emad F, Abdel-Mohsen M, Hoh R, Hecht F, Hunt P, Somsouk M, Wong J, Johnston R, Siliciano RF, Richman DD, O'Doherty U, Palmer S, Deeks SG, Siliciano JD. Comparative analysis of measures of viral reservoirs in HIV-1 eradication studies. PLoS Pathog. 2013;9:e1003174.

72. Malatinkova E, De Spiegelaere W, Bonczkowski P, Kiselinova M, Vervisch K, Trypsteen W, Johnson M, Verhofstede C, de Looze D, Murray C, Kinloch-de Loes S, Vandekerckhove L. Impact of a decade of successful antiretroviral therapy initiated at HIV-1 seroconversion on blood and rectal reservoirs. Elife. 2015;4:e09115.

73. Graf EH, Mexas AM, Yu JJ, Shaheen F, Liszewski MK, Di Mascio M, Migueles SA, Connors M, O'Doherty U. Elite suppressors harbor low levels of integrated HIV DNA and high levels of 2-LTR circular HIV DNA compared to HIV+ patients on and off HAART. PLoS Pathog. 2011;7:e1001300.

74. Morón-López S, Puertas MC, Gálvez C, Navarro J, Carrasco A, Esteve M, Manyé J, Crespo M, Salgado M, Martinez-Picado J. Sensitive quantification of the HIV-1 reservoir in gut-associated lymphoid tissue. PLOS ONE. 2017;12:e0175899.

75. Hey-Nguyen WJ, Xu Y, Pearson CF, Bailey M, Suzuki K, Tantau R, Obeid S, Milner B, Field A, Carr A, Bloch M, Cooper DA, Kelleher AD, Zaunders JJ, Koelsch KK. Quantification of residual germinal center activity and HIV-1 DNA and RNA levels using fine needle biopsies of lymph nodes during antiretroviral therapy. AIDS Res Hum Retroviruses. 2017;33:648-57.

76. Splettstoesser T. SciStyle Scientific Illustration [Internet]. http://www. scistyle.com.

\section{Submit your next manuscript to BioMed Central and we will help you at every step:}

- We accept pre-submission inquiries

- Our selector tool helps you to find the most relevant journal

- We provide round the clock customer support

- Convenient online submission

- Thorough peer review

- Inclusion in PubMed and all major indexing services

- Maximum visibility for your research

Submit your manuscript at www.biomedcentral.com/submit
BioMed Central 